\title{
The Perspectives of Amateur Soccer Players and their Coaches on the Use of Performance Enhancing Substances
}

\author{
Thanujj Kisten $^{1} \&$ Rowena Naidoo ${ }^{1}$ \\ ${ }^{1}$ Discipline of Biokinetics, Exercise and Leisure Sciences, University of KwaZulu-Natal, School of Health \\ Sciences, South Africa \\ Correspondence: Rowena Naidoo, University of KwaZulu-Natal, Discipline of Biokinetics, Exercise and Leisure \\ Sciences, Private Bag X54001, Durban 4000, South Africa. Tel: 27-31-260-8235; Fax: 27-31-260-7903. E-mail: \\ naidoor3@ukzn.ac.za
}

Received: June 1, 2018 Accepted: April 14, 2019 Online Published: June 25, 2019

doi:10.5539/gjhs.v11n7p154 URL: https://doi.org/10.5539/gjhs.v11n7p154

\begin{abstract}
Adolescent and youth sports seem to have progressively developed in South Africa to the point where young athletes are considering doping and the use of performance-enhancing substances (PES). This study determined the perspectives of U-19 soccer players and their coaches in the eThekwini region, KwaZulu-Natal, South Africa, on the use of supplements and drugs. Male participants $(n=449)$ playing first team soccer from development clubs in the eThekwini region, and their respective coaches $(\mathrm{n}=30)$, volunteered to participate in this study. A questionnaire was administered to players and coaches were interviewed. Soccer players and their coaches believed that consuming prohibited substances in sport was unethical. The majority of the players $(73.9 \%$ either agreed or strongly agreed) and coaches believed that doping in soccer is on the increase. About a quarter of the players consumed nutritional supplements and smoked cannabis. Anti-doping educational programmes and behaviour change interventions are vital in order to educate and transform athletes' and coaches' perspectives on doping and PES, and their resultant behaviour.
\end{abstract}

Keywords: supplements, cannabis, soccer players, coaches, doping

\section{Introduction}

Doping is regarded as a form of cheating, where athletes use substances that are on the prohibited list, predominantly for gaining an edge over their competitors. Coaches are often identified as a critical factor in an athlete's doping behaviour (Lazuras, Barkoukis, Rodafinos, \& Tzorbatzoudis, 2010) and are as important as potential agents in doping prevention (Kirby, Moran, \& Guerin, 2011; Cléret, 2011). A lack of engagement around the topic of doping issues by coaches, and pressure from management through a win-at-all-costs emphasis, were identified as factors that contributed to athletes making the decision to dope (Kirby et al., 2011).

An alternative to doping can be the use of a nutritional substances, which may help to improve the health and performance of active adolescent athletes (Gradidge, Coopoo, \& Constantinou, 2010). However, besides the growing concern of unintentional doping through the use of nutritional supplements, adolescent athletes' perceptions about the use of performance enhancing substances (PES), and how they may think it is acceptable to consume PES to give them an edge, is also of concern. A performance enhancing substance can be any substance taken in non-pharmacological doses, specifically for the purpose of improving sports performance. Dietary supplements, prescription medications and illicit drugs can be considered as PES (Gomez, 2005).

Backhouse, Whitaker and Petróczi (2013) reported on the 'gateway hypothesis' in their study of competitive collegiate athletes. This hypothesis predicts that the use of nutritional supplements, cannabis and/or alcohol can increase the risk of transitioning to PES or other 'hard' drugs such as steroids. Comparing non-users and regular nutritional supplement users, it was found that a significantly higher percentage of the nutritional supplement users reported that they doped (22.9\% vs 6\%). Individuals who used nutritional supplements had the perception that the use of PES to gain a favourable advantage in competition was acceptable and a viable option (Backhouse, Whitaker, \& Petróczi, 2013).

Morente-Sánchez and Zabala (2015) believed that team-based sports were less prone to doping practices than individual sports. However, there appears to be an increase in doping among adolescent and amateur soccer 
players. The use of local and traditional supplements among amateur soccer players from the African continent is increasing (Ama, Betnga, Ama Moor, \& Kamga, 2003).

In South Africa, an earlier study was conducted in 1992 on androgenic anabolic steroid use in secondary school learners (Grade 12) in the Western Cape (Nolte, 1992). Another study in 2010 (Gradidge et al., 2010) investigated the attitudes towards, and perceptions of, PES use in high school boys in Johannesburg. More recently, Nolte et al. (2014) studied the attitudes, beliefs and knowledge of talented young athletes (males and females) residing in Gauteng regarding prohibited PES and anti-doping rules and regulations. Results from these studies show an increase in the use of prohibited PES among the youth. Adolescent and youth sports seem to have developed to the point where young athletes are considering doping, including the use of PES.

\section{Purpose of Research}

Taking into consideration the increase in doping practices among soccer players, and the influence of coaches on their players, there appears to be a gap in the literature regarding players' and coaches' perspectives of PES. Moreover, studies on South African soccer players are limited, particularly in the province KwaZulu-Natal. The purpose of this study was to determine the perspectives of U-19 soccer players and their coaches on the use of PES in the eThekwini region, KwaZulu-Natal.

\section{Methods}

This study used a mixed-methods design. Ethical clearance was granted by the University's Human Resource Social Science Ethical Committee (HSS/0268/015M). The KwaZulu-Natal Department of Sports and Recreation granted permission to conduct the study on the players and coaches from soccer clubs in the eThekwini region.

A purposive sample comprised participants playing first team male U-19 soccer from 30 development clubs in the eThekwini region and their respective head coaches. The development league is a platform where scouts can recruit players to play in higher divisions. To be eligible to participate in the study, both the players and coaches had to be registered with their respective club for a minimum of six months.

Information sheets were handed out to participants outlining the purpose and possible outcomes of the study. Participants 18 years and over signed informed consent forms, while participants younger than 18 years signed assent forms and provided signed parental consent forms to participate in the study.

The player self-determined structured questionnaire was used to determine the attitudes, beliefs and knowledge of the athletes with regards to PES. The questionnaire was adapted from three studies, one local and two international (Ama et al., 2003; Nolte, Steyn, Krüger, \& Fletcher, 2014; Van Aswegen, 2014). A pilot study was conducted with 10 local soccer players that were not part of the selected development teams. No changes were necessary, based on feedback from the participants. The questionnaire was thereafter translated into isiZulu (the local language). Participants were given clear instructions on how to complete the questionnaire and anonymity was ensured in order to allow the participants to answer the questions as openly and honestly as possible.

Semi-structured interviews were conducted with each coach. The questions were based on the general perceptions and sources of information about prohibited substances and PES; knowledge of supplement use; and attitudes towards doping in sport. The 45-minute interview was recorded and transcribed accordingly.

Data collection was conducted during the off-season training sessions. The researchers were present to assist with any queries while players completed the questionnaire. Additionally, an IsiZulu translator was present for players as well as coaches. Data collection was completed within three weeks.

Descriptive statistics were conducted using SPSS Statistics 20 (IBM, USA) for the player questionnaire analysis. Responses from the coaches' interviews were analysed methodically by clustering themes and thereafter identifying patterns. To enhance and demonstrate the trustworthiness of the results, a peer-review process was employed to examine the thematic analysis.

\section{Results}

Thirty development soccer clubs from the eThekwini region volunteered to participate in this study. However, questionnaires were completed by 449 players from 29 development soccer clubs. Results of the questionnaire are presented in Tables 1 to 4 . Table 1 shows responses based on perceptions and knowledge of prohibited substances and PES, as well as attitudes towards doping. The majority of the players appear to agree or strongly agree that the use of prohibited substances is unethical, although their use is on the increase. Over half (52.1\%) of the sample was African (black) $(\mathrm{n}=234)$, with Asians (Indians) $(\mathrm{n}=113)$ and mixed-race respondents (Coloureds) $(\mathrm{n}=63)$ comprising $25.2 \%$ and $14 \%$, respectively. Whites $(n=39)$ were the smallest group, at $8.7 \%$. 


\subsection{Players' Questionnaires}

Table 1. General perceptions and knowledge of prohibited substances

\begin{tabular}{|c|c|c|c|}
\hline Questions & $\begin{array}{l}\text { Agreed or } \\
\text { strongly agreed }\end{array}$ & $\begin{array}{l}\text { Disagreed or } \\
\text { strongly disagreed }\end{array}$ & Neutral \\
\hline The use of prohibited substances in sport is unethical & $74.4 \%$ & $16.3 \%$ & $9.3 \%$ \\
\hline The use of prohibited substances in sport is increasing & $73.9 \%$ & $9.6 \%$ & $16.5 \%$ \\
\hline $\begin{array}{l}\text { Athletes are being pressured to use prohibited substances (by } \\
\text { coaches, media, their parents etc.) }\end{array}$ & $55.2 \%$ & $31.2 \%$ & $13.6 \%$ \\
\hline $\begin{array}{l}\text { A drug testing programme will prevent the use of supplements in } \\
\text { school sports }\end{array}$ & $82.2 \%$ & $11.3 \%$ & $6.5 \%$ \\
\hline $\begin{array}{l}\text { I am familiar with the current prohibited list of substances and } \\
\text { supplements as indicated by the World Anti-Doping Agency }\end{array}$ & $51 \%$ & $31.2 \%$ & $17.8 \%$ \\
\hline I am aware of the punishment for doping offences in sport & $78.4 \%$ & $10.7 \%$ & $10.9 \%$ \\
\hline
\end{tabular}

Almost three-quarters of the participants (Table 2) obtain information on supplementation from their coaches, books and personal trainers. The players may not always have their own personal trainers, but have friends or colleagues who are personal trainers. At least a quarter (42.3\%) of the participants currently do not use PES.

Table 2. Sources of information regarding supplementation and use of supplements

\begin{tabular}{lll}
\hline Responses & Yes & No \\
\hline Pharmacist & $69.5 \%$ & $30.5 \%$ \\
General Practitioner & $65 \%$ & $35 \%$ \\
Personal Trainer & $73.9 \%$ & $26.1 \%$ \\
Coach & $74.6 \%$ & $25.4 \%$ \\
Biokineticist/Trainer & $59.7 \%$ & $40.3 \%$ \\
Parent & $53.2 \%$ & $46.8 \%$ \\
Sibling & $46.3 \%$ & $53.7 \%$ \\
Internet & $72.4 \%$ & $27.6 \%$ \\
Books & $74.2 \%$ & $25.8 \%$ \\
Magazines & $67.7 \%$ & $32.3 \%$ \\
Videos & $65.7 \%$ & $34.3 \%$ \\
\hline Use of supplements & & \\
Response & Frequency & Percentage \\
\hline Yes, currently use & 111 & 24.7 \\
Yes, but have discontinued usage & 148 & 33.0 \\
No, never used & 190 & 42.3 \\
\hline
\end{tabular}

The more popular magazines mentioned were Men's Health; FIFA; USN; Sport Science Nutrition; body building magazines and Laduma. Television, posters and flyers were also used as sources by the participants. With regards to internet sources, the majority of participants used search engines such as Google, Yahoo and Bing to find information about supplementation. Google was used by $85.2 \%$ of the sample. More than one-third (38.4\%) of participants viewed You Tube videos about supplementation to gather information. The sites reported as least viewed were USN (12.1\%), Wikipedia (12.5\%) and body building websites (6.1\%). 
The majority of the participants appear to have a positive attitude towards anti-doping (Table 3).

Table 3. Attitudes towards doping in sport

\begin{tabular}{|c|c|c|c|}
\hline Questions & $\begin{array}{l}\text { Agreed or } \\
\text { strongly agreed }\end{array}$ & $\begin{array}{l}\text { Disagreed or } \\
\text { strongly disagreed }\end{array}$ & Neutral \\
\hline $\begin{array}{l}\text { Sport organisations should offer educational programmes for } \\
\text { athletes on the use of substances in sport }\end{array}$ & $86.4 \%$ & $8.7 \%$ & $4.9 \%$ \\
\hline $\begin{array}{l}\text { There are too many athletes in South Africa using substances to } \\
\text { enhance their athletic performance in my sport }\end{array}$ & $71.5 \%$ & $11.1 \%$ & $17.4 \%$ \\
\hline $\begin{array}{l}\text { There are too many athletes world-wide using substances to } \\
\text { enhance their athletic performance in my sport }\end{array}$ & $72.4 \%$ & $12.2 \%$ & $15.4 \%$ \\
\hline $\begin{array}{l}\text { The illegal use of substances by athletes has not been reported on } \\
\text { enough by the media }\end{array}$ & $71.3 \%$ & $16.9 \%$ & $11.8 \%$ \\
\hline The use of PES and supplements has risen in the last five years & $72.8 \%$ & $11.4 \%$ & $15.8 \%$ \\
\hline Taking prohibited/illegal substances is harmful to my health & $84.4 \%$ & $9.4 \%$ & $6.2 \%$ \\
\hline
\end{tabular}

Reasons for PES use (Table 4) were predominately personal and social. Almost a third of the participants consumed PES for sport-related purposes, like recovery or nutrition.

Table 4. Reasons for consuming PES

\begin{tabular}{|c|c|c|c|}
\hline Responses & $\begin{array}{l}\text { Agreed or strongly } \\
\text { agreed }\end{array}$ & $\begin{array}{lll}\text { Disagreed } & \text { or } & \text { strongly } \\
\text { disagreed } & & \end{array}$ & Neutral \\
\hline Recreational or social reasons & $64.8 \%$ & $18 \%$ & $7.2 \%$ \\
\hline Assisting me in coping with the stresses of sport & $31.6 \%$ & $32.4 \%$ & $36 \%$ \\
\hline Assisting me in coping with life's stresses & $61.3 \%$ & $21.6 \%$ & $17.1 \%$ \\
\hline Improving my sport performance & $43.2 \%$ & $39.8 \%$ & $27 \%$ \\
\hline The good feeling they give me & $69.3 \%$ & $19 \%$ & $11.7 \%$ \\
\hline Enhancing recovery & $28.8 \%$ & $54.1 \%$ & $17.1 \%$ \\
\hline Counteracting tiredness & $20.7 \%$ & $63.1 \%$ & $16.2 \%$ \\
\hline Meeting nutrient needs & $27.9 \%$ & $55 \%$ & $17.1 \%$ \\
\hline Increasing my energy & $30.6 \%$ & $52.3 \%$ & $17.1 \%$ \\
\hline
\end{tabular}

Table 5 shows smoking, alcohol consumption and cannabis use by participants who currently use, or have previously used, PES.

Table 5. Smoking, alcohol consumption and cannabis use (PES-users)

\begin{tabular}{lll}
\hline Smoking and alcohol consumption & & \\
\hline Questions & $47.7 \%$ & No \\
\hline Do you smoke before matches & $59.5 \%$ & $42.3 \%$ \\
Do you smoke after matches & $32.4 \%$ & $67.6 \%$ \\
Do you drink alcohol before matches & $65.8 \%$ & $34.2 \%$ \\
Do you drink alcohol after matches & & \\
\hline
\end{tabular}




\begin{tabular}{lll}
\hline Cannabis knowledge and use & & \\
\hline Questions & Yes & No \\
\hline Do you know of banga (marijuana) & $91.9 \%$ & $8.1 \%$ \\
Do you know of wie-wie (a locally manufactured powdered traditional product) & $77.5 \%$ & $22.5 \%$ \\
Do you know of iboga (a hallucinogenic drug) & $69.4 \%$ & $30.6 \%$ \\
Do you know of cocaine & $68.5 \%$ & $31.5 \%$ \\
Do you use banga (marijuana) & $70.3 \%$ & $29.7 \%$ \\
Do you use wie-wie (a locally manufactured powdered traditional product) & $8.1 \%$ & $91.9 \%$ \\
Do you use iboga (a hallucinogenic drug) & $12.6 \%$ & $87.4 \%$ \\
Do you use coccaine & $36.9 \%$ & $63.1 \%$
\end{tabular}

The incidence of marijuana smoking is high among the participants $(70.3 \%)$. The use of cocaine $(36.9 \%)$ is of major concern.

\subsection{Coaches Interview}

The following themes emerged among coaches regarding their perceptions of prohibited substances: the use of illegal substances is unethical; substances on the WADA prohibited substance list; and source/s of information.

4.2.1 The use of illegal substances in sport is unethical:

The coaches felt that the use of illegal substances gave athletes an unfair advantage against rivals who cannot afford such substances. Additionally, there are many harmful side-effects associated with the use of these substances, which can affect the athlete in the long-term. However, coaches expressed the opinion that if these substances were provided to all 22 players on the field, then it could be considered fair. Statements reported by coaches included:

"It is against the principle of sport to dope. It is unfair to the people who cannot afford them." "It is discomforting to see our youngsters consuming prohibited substances to get an edge. Training is vital but prohibited substances give an unfair edge."

"Everything should be all natural and you should be dependent on your own ability rather than having substances to enhance your performance." "Gives an unfair advantage to individuals and the harmful effects heavily outweigh the positive gains."

\subsubsection{Substances on the WADA Prohibited Substance List}

The coaches were unfamiliar with the substances that were on the published WADA prohibited list. However, they were knowledgeable about the common prohibited substances. Furthermore, coaches were unaware that the prohibited list is updated yearly. Comments expressed by coaches included:

"I have an idea but I don't know the list in detail." "I am aware of the common prohibited substances or methods such as blood doping."

\subsubsection{Sources of Information}

The majority of the coaches sourced their information about supplementation for the players from the internet, Sports Illustrated magazine, health shops, USN brochures, experienced coaches, media such as television, dieticians, sport physicians and biokineticists.

Comments reported included:

"I source my information from reliable sources such as sport physicians, fellow experienced coaches and biokineticists." "Although I rarely source information about supplementation, if I had to I would source them from management staff, fellow colleagues, media, sports magazines and experienced coaches."

\subsubsection{Knowledge About Supplement Use}

The following themes emerged among coaches regarding their knowledge about supplement use: consumption of supplements; consumption of cannabis or PES; consequences of doping.

\subsubsection{Consumption of Supplements}

Players held mixed views about the use of supplements. At least half of the coaches believed that their players 
should be taking PES. Many of the coaches believed that their players would not be able to afford substances or supplements.

Coaches who recommended that their players consume supplements often recommended protein shakes, energy drinks such as Monster, creatine supplements and glutamine. However, the majority of the coaches were not aware of what their players were consuming, specifically at practices or matches in the absence of a coach.

\subsubsection{Consumption of Cannabis or PES}

The coaches were adamant about the use of cannabis and they made a rule that if any player was caught taking drugs, they would be barred from the club. These were some of the comments voiced by coaches:

"I have outlawed the consumption of any drugs. If caught I make sure that they are kicked out of the club"

"My players cannot afford to buy drugs" "I assume they do not take, although I cannot say for sure."

\subsubsection{Consequences of Doping}

Coaches believed that their players were aware of the consequences if they were caught doping. However, coaches were not well informed about the range of sanctions that can be imposed on a player. Many of the coaches reported that they were aware of cases where players were caught doping in other sports.

\subsubsection{Attitudes Towards Doping}

The following themes emerged among coaches regarding their attitude towards doping: doping is a problem in soccer; media documentation of doping; doping in South Africa and internationally; the need for educational programmes.

\subsubsection{Doping is a Problem in Soccer:}

The majority of the coaches believed that doping is prevalent among players. However, the problem of doping in soccer is minimal when compared to sports such as rugby and athletics. Coaches accept that doping is an addiction.

\subsubsection{Media Documentation of Doping}

Coaches believed that the media frequently do not document or report the cases of doping, especially at U-19 club level soccer. Local cases should receive more exposure in the media. Coaches also believed that educational programmes about doping should be publicised in the media.

\subsubsection{Doping in South Africa and Internationally}

Coaches reported that there is a problem with doping in South Africa; but more so in international sports. They believed that, to meet the high demands of the professional game, a player has to dope. Furthermore, players are accessing doping supplements more easily as substances are easily available. Comments included:

"I do not believe that there is drug-free sport at a high level. In all sports there is doping, because to win you have to be excellent; and it is difficult to achieve excellence without doping." "I can't see how a player is able to keep up such an intensity for 90 minutes without doping."

"Players are uneducated about doping, so if they are told that if you take this it will make you play better, they are going to try it."

\subsubsection{The Need for Educational Programmes}

Coaches believed that education about doping should start from school-boy level. Comments included:

"Educational programmes will help our players learn about risks of doping and also learn about alternatives to doping."

"It would make them aware of what is legal and what is illegal. Will also make them aware of procedures on doping check-ups."

\section{Discussion}

Peretti-Watel et al. (2004) noted that the majority (90\%) of athletes believed that doping is dishonest, unhealthy or very dangerous to an individual's health. Similarly, in this study, $37 \%$ of athletes agreed that taking prohibited substances in sport is unethical; whilst $37.4 \%$ strongly agreed with this statement. The majority of U-19 soccer players also believed that the use of prohibited substances in sport is on the increase and that drug testing or anti-doping programmes will help prevent the use of banned substances in schools.

In this study, most players are of the belief that they are being pressured into taking prohibited substances to enhance performance. Approximately a quarter (25.8\%) of participants agreed with this statement; while $29.4 \%$ 
strongly agreed with this statement. Sanchez and Zabala (2013) found that $6.5 \%$ of players were pressured by coaches to consume PES; whilst Gradidge, Coopoo and Constantinou (2010) found that $84 \%$ of athletes felt pressured to use PES in order to win. Ajzen (1991) reported on the Theory of Planned Behaviour. Lazuras et al. (2010) reported on 'situational temptation' with reference to this theory. Situational temptation focuses on coaches' suggestions; athletes' belief that teammates were consuming PES; expectations that athletes improve their performance; and whether they would take PES in preparation for an important game (Lazuras et al., 2010). It was found that there was greater intention amongst players to dope when these factors are present. It can therefore be assumed that, if coaches pressure specific players to consume PES, and their teammates are aware of it, or if players feel pressured to win, then the players are more likely to dope in order to improve their performance to the level of their teammates, who are already consuming PES.

Access to information and athletes' sources of information are critical for them to make informed and justifiable decisions. Waddington et al. (2005) reported that more than $50 \%$ of participants wanted additional information regarding supplement use; whilst Erdman et al. (2007) stated that $63.2 \%$ of players had access to anti-doping information. In this study, the majority of U-19 soccer players reported that they gathered information about doping and supplement use from coaches, the internet, books, personal trainers, pharmacists, magazines and videos. The lowest percentages of participants chose to seek information from general practitioners, biokineticists, parents and siblings. These findings indicate that most of our youth soccer players, as well as their coaches, do not source scientifically-based information regarding nutrition and do not consult with a dietician or other registered practitioner.

In this study, $28.7 \%$ of U-19 soccer players agreed that they were familiar with the current list of prohibited substances, as indicated by the WADA; while $22.3 \%$ strongly agreed. Of the participants, $49 \%$ were not familiar with the list. The majority of coaches also reported that they were not familiar with the substances or supplements that were on the WADA banned list. Similarly, a study conduct by Sanchez and Zabala (2015) found that $84.9 \%$ of coaches were not familiar with the WADA list of banned substances; whilst over half of the coaches did not know what the acronym WADA meant. Giraldi et al. (2015) also reported that coaches and athletes show a significant lack of knowledge about supplementation. From these findings, we can deduce that there is a clear lack of education regarding prohibited substances. This lack of knowledge by both players and coaches can, in turn, lead to more incidents of doping. A study conducted by Erdman et al. (2007) found that $76.7 \%$ of respondents reported that they were aware of the anti-doping regulations and $89.5 \%$ of athletes believed that they were following these rules. However, only $63.2 \%$ of the athletes reported that they had access to anti-doping information. This lack of knowledge is concerning and can result in unintentional doping by athletes.

In this study, 78.4\% players stated that they are aware of the consequences of doping. Nieper (2005) reported that just over half (50.5\%) of athletes knew the consequences if caught doping. However, players were unaware of the new 2015 WADA sanctions; i.e. athletes can receive a four-year ban from competition for a first offense for obtaining, consuming and attempting to use prohibited substances (2015 WADA Code Changes|U.S. Anti-Doping Agency (USADA), n.d.). Findings indicate that athletes need more education about the consequences of doping, which could impact on their perceptions about consuming PES and prohibited substances.

\subsection{Patterns of Substance Use}

In this study, $24.7 \%$ of soccer players admitted to consuming PES, cannabis, smoke and/or alcohol. A further $33 \%$ of participants had admitted to consuming these substances at least once, but had discontinued consumption. Coaches had mixed views on whether they would recommend PES for their players. A similar study conducted by Gradidge, Coopoo and Constantinou (2011) found that 30\% of adolescent boys from Johannesburg high schools admitted to using PES. Backhouse, Whitaker and Petróczi (2013) reported on a 'gateway hypothesis'. This hypothesis states that athletes who consume nutritional supplements, cannabis or alcohol run an increased risk of transitioning to consuming illegal substances and doping.

Sanchez and Zabala (2013) reported that the main reasons for consuming PES were to achieve athletic success, improve self-confidence, and for social recognition. Another study conducted by Gradidge, Coopoo and Constantinou (2010) found that $84 \%$ of athletes in Johannesburg high schools consumed PES, cannabis, alcohol and/or smoked, as they felt pressured to win. The majority of athletes indicated that they use PES to improve performance; to help reduce food cravings - thus decreasing body weight; and to cope with the stress that sport places upon them. Kirby, Moran and Guerin (2011) noted that a lack of communication about doping by coaches, and pressure from management through a win-at-all-costs approach, were identified as factors that contributed to athletes' deciding to dope. Furthermore, Backhouse and Mckenna (2012) reported that $30 \%$ of coaches believe if players do not consume PES or dope, they have very little chance of success. Hence, athletes feel pressured to use 
PES in order to perform at a high level and to win.

The majority of the soccer players began PES consumption in high school. Players believed that their coaches were unaware of their PES, cannabis and/or alcohol consumption. On the other hand, coaches believed that they were aware of their players' substance use. It appears that coaches are unaware of substance use among players, particularly during non-practice and match days.

Players in this study reported that they have used creatine, protein shakes, testosterone boosters and USN products. Coaches interviewed in this study also advised their players to consume protein shakes, energy drinks such as Monster, creatine supplements and glutamine. The similarities between coaches' suggestions and their influence on players is evident. The current study showed that players smoked and consumed alcohol before and after matches. Moreover, players also admitted to consuming drugs such as banga (marijuana), wie-wie (a locally manufactured powdered traditional product), iboga (a hallucinogenic drug) and cocaine. Almost a third of the players consumed banga before matches. The high usage of these substances could be due to their easy availability. However, coaches believed that their players do not consume cannabis due to their strict policy against the use of cannabis. Thus, findings indicate that coaches are unaware of substances consumed by their players.

\subsection{Attitudes About Doping in Sport}

One-third of the soccer players agreed that many athletes in South Africa consume PES. The majority of players either agreed or strongly agreed that the use of PES or supplements has increased over the past five years. A study conducted in Australia reported that athletes who believe their teammates are consuming PES are more likely to partake in such practices. Additionally, the study indicated that $19 \%$ of athletes felt that PES were widely consumed by other athletes and a further $30 \%$ believed that recreational drugs are consumed by other athletes (Moston, Engelberg, \& Skinner, 2014).

The theme that doping is a minor problem in local soccer, as opposed to a major problem in international soccer, emerged from the coaches' interviews. The Theory of Reflection can assist in analysing coaches' perceptions of their roles and how this relates to their actions. The logic behind this theory is that coaches frame their role according to what information is most pertinent to them; which issues are identified as 'problematic'; and what strategies are developed to address them (Schoen, 1983). With regards to this study, coaches believe that doping is a problem in soccer, but not a major problem or priority. As a result, the risk of an athlete doping may not be identified or dealt with accordingly.

A study conducted by Backhouse, Whitaker and Petróczi (2013) used a 'gateway hypothesis', which predicts that the consumption of nutritional supplements, cannabis or alcohol can increase the risk of transitioning to use of PES or prohibited substances. Based on the Theory of Reflection and the findings from the current study, the problem of doping in sport may never be addressed. Coaches have a pivotal role in doping and the prevention thereof. If coaches do not discuss the consumption of PES with athletes, then athletes may find it acceptable to consume PES; which, according to Backhouse, Whitaker and Petróczi (2013), may lead to more incidences of doping.

In this study, $32.1 \%$ of soccer players agreed, and a further $54.3 \%$ of participants strongly agreed, that sport organisations should provide more educational programmes about the use of supplements. These sentiments were also commonly expressed by coaches. Many studies indicate the major lack of knowledge and education around the topic of doping and substance use (Ali, Al-Siya, Waly, \& Kilani, 2015; Giraldi et al., 2015; Morente-Sánchez \& Zabala, 2015; Nieper, 2005; Waddington et al., 2005). Kirby, Moran and Guerin (2011) found that only 10\% of coaches in France had organised a doping prevention programme during the previous year; although they understood that they played an crucial role in preventing doping among players. Another study conducted by Laure, Thouvenin and Lecerf (2001) reported that $80 \%$ of French coaches believed that the current structures implemented by sports organisations are not effective enough in reducing doping. A further $73 \%$ of these coaches believed that more training and educational programmes should be implemented to reduce doping, and that stricter control of doping in sport should be implemented. This lack of education and knowledge about doping among coaches could, in turn, explain the low number of prevention programmes provided by coaches. There is a need for sports organisations to implement and deliver more educational programmes to effectively educate athletes, as well as coaches, about substance use and anti-doping regulations.

\section{Conclusion}

There is a definite lack of knowledge by players and, to an extent, coaches on the topic of doping in sport and the consumption of PES. Furthermore, coaches are unaware of the doping practices of their players. Anti-doping educational programmes and behaviour-change interventions are vital in order to transform athletes' and coaches' perspectives on doping and PES, and their resultant behaviour. 


\section{Acknowledgements}

We acknowledge the support from the University of KwaZulu-Natal's College of Health Sciences, the South African Institute for Drug-Free Sport (SAIDS) and the World Anti-doping Agency (WADA).

\section{Competing Interests Statement}

The authors declare that there are no competing or potential conflicts of interest.

\section{References}

2015 WADA Code Changes|U.S. Anti-Doping Agency (USADA). (n.d.). Retrieved December 12, 2015, from http://www.usada.org/resources/2015code/

Ajzen, I. (1991). The theory of planned behavior. Organizational Behavior and Human Decision Processes, 50(2), 179-211. https://doi.org/10.1016/0749-5978(91)90020-T

Ali, A., S. Al-Siya, M., Waly, M. I., \& Kilani, H. A. (2015). Assessment of Nutritional Knowledge, Dietary Habits and Nutrient Intake of University Student Athletes. Pakistan Journal of Nutrition, 14(5), 293-299. https://doi.org/10.3923/pjn.2015.293.299

Ama, P., Betnga, B., Ama Moor, V. J., \& Kamga, J. P. (2003). Football and doping: study of African amateur footballers. British Journal of Sports Medicine, 37(4), 307-310. https://doi.org/10.1136/bjsm.37.4.307

Backhouse, S. H., \& McKenna, J. (2012). Reviewing Coaches' Knowledge, Attitudes and Beliefs Regarding Doping in Sport. International Journal of Sports Science and Coaching, 7(1), 167-176. https://doi.org/10.1260/1747-9541.7.1.167

Backhouse, S. H., Whitaker, L., \& Petróczi, A. (2013). Gateway to doping? Supplement use in the context of preferred competitive situations, doping attitude, beliefs, and norms. Scandinavian Journal of Medicine \& Science in Sports, 23(2), 244-252. https://doi.org/10.1111/j.1600-0838.2011.01374.x

Erdman, K., Fung, T., Doyle-Baker, P., Verhoef, M., \& Reimer, R. (2007). Dietary supplementation of high-performance Canadian athletes by age and gender. Clinical Journal of Sport Medicine, 17(6), 458-464. Retrieved from http://journals.lww.com/cjsportsmed/Abstract/2007/11000/Dietary_Supplementation_of _High_performance.4.aspx

Giraldi, G., Unim, B., Masala, D., Miccoli, S., \& La Torre, G. (2015). Knowledge, attitudes and behaviours on doping and supplements in young football players in Italy. Public Health, 129(7), 1007-1009. https://doi.org/10.1016/j.puhe.2015.05.008

Gradidge, P., Coopoo, Y., \& Constantinou, D. (2010). Attitudes and perceptions towards performanceenhancing substance use in Johannesburg boys high school sport. South African Journal of Sports Medicine. Health and Medical Publishing Group. Retrieved from http://www.ajol.info/index.php/sasma/article/view/70169

Gradidge, P., Coopoo, Y., \& Constantinou, D. (2011). Prevalence of performance-enhancing substance use by Johannesburg male adolescents involved in competitive high school sports. Archives of Exercise in Health and Disease. https://doi.org/10.5628/aehd.v2i2.102

Kirby, K., Moran, A., \& Guerin, S. (2011). A qualitative analysis of the experiences of elite athletes who have admitted to doping for performance enhancement. International Journal of Sport Policy and Politics, 3(2), 205-224. https://doi.org/10.1080/19406940.2011.577081

Laure, P., Thouvenin, F., \& Lecerf, T. (2001). Attitudes of coaches towards doping. The Journal of Sports Medicine and Physical Fitness, 41(1), 132-136. Retrieved from http://www.ncbi.nlm.nih.gov/pubmed/11317161

Lazuras, L., Barkoukis, V., Rodafinos, A., \& Tzorbatzoudis, H. (2010). Predictors of doping intentions in elite-level athletes: a social cognition approach. Journal of Sport \& Exercise Psychology, 32, 694-710.

Morente-Sánchez, J., \& Zabala, M. (2013). Doping in sport: a review of elite athletes' attitudes, beliefs, and knowledge. Sports Medicine (Auckland, N.Z.), 43(6), 395-411. https://doi.org/10.1007/s40279-013-0037-x

Morente-Sánchez, J., \& Zabala, M. (2015). Knowledge, attitudes and beliefs of technical staff towards doping in Spanish football. Journal of Sports Sciences, 3(12), 1267-1275. https://doi.org/10.1080/02640414.2014.999699

Moston, S., Engelberg, E. T., \& Skinner, J. (2014). Perceived incidence of drug use in Australian sport: a survey of athletes and coaches. Sport in Society, 18(1), 91-105. https://doi.org/10.1080/17430437.2014.927867

Nieper, A. (2005). Nutritional supplement practices in UK junior national track and field athletes. British Journal 
of Sports Medicine, 39(9), 645-649. https://doi.org/10.1136/bjsm.2004.015842

Nolte, K., Steyn, B., Krüger, P., \& Fletcher, L. (2014). Doping in sport: Attitudes, beliefs and knowledge of competitive high-school athletes in Gauteng Province. South African Journal of Sports Medicine, 26, 81-86. Retrieved from http://www.scielo.org.za/scielo.php?pid=S2078-516X2014000100005\&script=sci arttext\&tlng=en

Peretti-Watel, P., Guagliardo, V., Verger, P., Mignon, P., Pruvost, J., \& Obadia, Y. (2004). Attitudes toward doping and recreational drug use among french elite student-athletes. Sociology of Sport Journal, 21(1), 1-17.

Schoen, D. (1983). The Reflective Practitioner: How professionals think in action. Retrieved from http://cumincad.scix.net/cgi-bin/works/Show?9e1a

Van Aswegen, M. (2014, August 25). The knowledge, attitudes and use of performance enhancing substances and supplements among male high school first-and second team athletes in the central metropolitan area of Cape Town, South Africa. Retrieved from http://wiredspace.wits.ac.za/handle/10539/15239

Waddington, I., Malcolm, D., Roderick, M., \& Naik, R. (2005). Drug use in English professional football. British Journal of Sports Medicine, 39(4), e18.

\section{Copyrights}

Copyright for this article is retained by the author(s), with first publication rights granted to the journal.

This is an open-access article distributed under the terms and conditions of the Creative Commons Attribution license (http://creativecommons.org/licenses/by/4.0/). 